\title{
Alterações hematológicas após implante de matriz óssea desmineralizada caprina em modelo de defeito ulnar crítico em coelhos*
}

\section{Hematological Changes after Caprine Demineralized Bone Matrix Implantation in Ulnar Critical Defect of Rabbit Model}

\author{
Olawale Alimi Alimi ${ }^{1,2}$ Adamu Abdul Abubakar ${ }^{2}$ Abubakar Sadiq Yakubu ${ }^{2}$ Ab \\ Sani Abdullahi Shehu ${ }^{30}$ Salman Zubairu Abdulkadir ${ }^{1,2}$ Ekaete Ime Oviawe $^{20}$ \\ ${ }^{1}$ Departamento de Cirurgia e Radiologia Veterinária, University of \\ Endereço para correspondência Olawale Alimi Alimi, DVM, \\ llorin, llorin, Nigéria \\ 2 Departamento de Cirurgia e Radiologia Veterinária, Usmanu \\ Department of Veterinary Surgery and Radiology, University of Ilorin, \\ Danfodiyo University, Sokoto, Nigéria \\ ${ }^{3}$ Departamento de Anatomia Veterinária, Usmanu Danfodiyo University, \\ Sokoto, Nigéria \\ Rev Bras Ortop 2022;57(2):218-222.
}

\begin{abstract}
Resumo
Objetivo Diversos modelos animais têm sido usados em estudos sobre enxertos ósseos e o tratamento de fraturas, mas as respostas hematológicas são raramente relatadas. Este estudo descreveu as alterações hematológicas observadas em coelhos submetidos a xenoenxertos de matriz óssea desmineralizada caprina (MODC). Métodos Vinte e quatro (24) coelhos machos $(2,5 \pm 0,5 \mathrm{~kg}$ ) foram adquiridos para este estudo e divididos aleatoriamente em três grupos: enxerto ósseo autólogo (EOA); controle negativo sem preenchimento (SP) e matriz óssea desmineralizada caprina (MODC). Amostras de sangue foram coletadas por punção cardíaca sob anestesia com xilazina-quetamina no dia 0 (para estabelecimento dos valores basais) e aos dias 28 e 56 após a cirurgia; essas amostras foram submetidas à análise manual em até 2 horas após

Palavras-chave

- enxerto ósseo

- xenoenxerto ósseo

- modelo animal experimental

- consolidação da fratura

- hematologia a coleta. A análise estatística foi composta por análise de variância (ANOVA) de dois fatores com medidas repetidas, e o valor de $p<0,05$ foi considerado significativo. Resultados Houve uma diferença geral significativa nos números de leucócitos totais ( $p=0,0043)$, neutrófilos $(p<0,0001)$, monócitos $(p=0,0184)$ e hemácias $(p=0,003)$, na concentração de hemoglobina $(p<0,0001)$ e no hematócrito $(p<0,0001)$ ao longo dos dias e entre os grupos de tratamento. No entanto, não houve diferença global significativa no número de linfócitos $(p=0,4923)$, basófilos $(p=0,4183)$ e eosinófilos $(p=0,4806)$ entre os dias.
\end{abstract}

\footnotetext{
Estudo desenvolvido no Departamento de Cirurgia Veterinária e

Radiologia Usmanu Danfodiyo University, Sokoto, Nigéria.
}

recebido

29 de Agosto de 2020

aceito

08 de Janeiro de 2021

Publicado on-line

Agosto 13, 2021
DOI https://doi.org/ $10.1055 / \mathrm{s}-0041-1729592$ ISSN 0102-3616.
(C) 2021. Sociedade Brasileira de Ortopedia e Traumatologia. All rights reserved.

This is an open access article published by Thieme under the terms of the Creative Commons Attribution-NonDerivative-NonCommercial-License, permitting copying and reproduction so long as the original work is given appropriate credit. Contents may not be used for commercial purposes, or adapted, remixed, transformed or built upon. (https://creativecommons.org/ licenses/by-nc-nd/4.0/)

Thieme Revinter Publicações Ltda., Rua do Matoso 170, Rio de Janeiro, RJ, CEP 20270-135, Brazil 


\begin{abstract}

Abstract

Keywords
- bone grafting
- bone xenograft
- experimental animal
- model
- fracture healing

Objective Several animal models have been used in fracture healing and bone graft studies, but hematological responses are seldom reported. Therefore, the present study reported the hematological changes observed in rabbits that underwent xenografting of caprine demineralized bone matrix (CDBM).

Method Twenty-four (24) male rabbits $(2.5 \pm 0.5 \mathrm{~kg})$ were acquired for the purpose of this study and were randomly assigned to three groups: autologous bone graft (ABG), unfilled (NC), and caprine demineralized bone matrix (CDBM). Blood samples were collected through cardiac puncture under xylazine-ketamine anesthesia on day 0 (baseline), and on days 28 and 56 postsurgery and were analyzed manually within 2 hours of collection. Statistical analysis was performed using a two-way analysis of variance (ANOVA) with repeated measures, and a $p$-value $<0.05$ was considered significant.

Result There was an overall significant difference in the values of total white blood cell count $(p=0.0043)$, neutrophil count $(p<0.0001)$, monocyte count $(p=0.0184)$, red blood cell count $(p=0.003)$, hemoglobin concentration $(p<0.0001)$ and packed cell volume $(p<0.0001)$ across the days and the treatment groups. There was, however, no overall significant difference in lymphocyte count $(p=0.4923)$, basophil count $(p=0.4183)$, and eosinophil count $(0.4806)$ within days.

Conclusion Response to CDBM grafting in rabbits could, therefore, be said to be characterized by marked leukocytosis with neutrophilia, lymphocytosis, and monocytosis by day 28 of postgrafting. This could form the basis with which hematology can be used to monitor body response of bone graft animal models.
\end{abstract}

Conclusão A resposta ao enxerto de MODC em coelhos é, portanto, caracterizada por leucocitose intensa com neutrofilia, linfocitose e monocitose no $28^{\circ}$ dia após o procedimento. Esses dados podem basear a utilização da hematologia no monitoramento da resposta corporal em modelos animais de enxerto ósseo.

\section{Introdução}

O sangue reflete o estado de qualquer animal e, assim, tem sido usado para conhecer estados fisiológicos e patológicos e em avaliações diagnósticas e prognósticas de várias doenças. ${ }^{1-4} \mathrm{~A}$ análise hematológica é, portanto, realizada para investigar metabólitos no corpo e respostas à exposição a antígenos e doenças em animais, pois diferentes patologias ou a exposição a certas condições influenciam alguns parâmetros sanguíneos específicos. ${ }^{1,5-7}$

Deve-se ter cuidado ao usar o hemograma com fins diagnósticos em coelhos, pois os parâmetros hematológicos são afetados por muitos fatores. Idade, sexo, raça, temperatura ambiente, ritmo diurno e até mesmo o transporte foram relatados como causas de alterações no hemograma de coelhos. ${ }^{8}$ Linfocitopenia, leucocitose e aumento do hematócrito, por exemplo, foram relatados em coelhos transportados a $28^{\circ} \mathrm{C}$ por até 3 horas, enquanto o estresse pelo frio aumentou o número de hemácias. Além disso, o número de leucócitos é variável por sofrer flutuações diurnas, sendo menor no final da tarde e à noite em comparação às primeiras horas do dia. $^{8} \mathrm{O}$ número de hemácias também varia de acordo com o sexo do animal e é ligeiramente maior em coelhos machos em comparação às fêmeas. ${ }^{8}$ Doenças infecciosas normalmente não causam leucocitose em coelhos, mas mudam as contagens diferenciais, passando da predominância de linfócitos para a predominância de neutrófilos; ademais, as infecções agudas podem ser caracterizadas por leucopenia com contagem diferencial normal. ${ }^{8}$ Anemia, neutrofilia, leucocitose e monocitose foram relatadas em um modelo de coccidiose hepática em coelhos, contrastando com a eosinofilia conhecida por acompanhar as doenças parasitárias em outros animais. ${ }^{8}$

O monitoramento dos parâmetros hematológicos tem papel vital na cicatrização de fraturas, já que qualquer desvio do intervalo de referência pode ser uma indicação de infecção ou resposta ao enxerto e, assim, requer atenção urgente para evitar a possibilidade de consolidação inadequada, tardia ou ausente. ${ }^{9}$ A hematologia é, no entanto, caracterizada por flutuações dentro das faixas fisiológicas normais, o que pode dificultar sua utilidade diagnóstica. ${ }^{9}$ A diminuição no número total de hemácias é observada após trauma e cirurgia. ${ }^{9}$ Estresse, trauma e cirurgia são conhecidos por causar leucocitose, linfocitopenia e neutrofilia, com números que também podem flutuar dentro dos limites normais após a diminuição do problema inicial. $O$ aumento ou redução do número de basófilos, monócitos e eosinófilos pode ser subjetivo no monitoramento da consolidação da fratura. ${ }^{9}$ Devido à escassez de informações sobre a resposta hematológica à consolidação de fratura em modelos animais, este estudo relata as alterações hematológicas observadas em coelhos submetidos a xenoenxertos de matriz óssea desmineralizada caprina. 


\section{Materiais e Métodos}

\section{Delineamento Experimental}

Este estudo foi aprovado pelo comitê de ética em pesquisa com animais da faculdade sob o número UDUS/FAREC/2019/ AUP-R0-5. Vinte e quatro coelhos machos $(2,5 \pm 0,5 \mathrm{~kg})$ foram divididos aleatoriamente em 3 grupos de 8 indivíduos. Cada grupo foi submetido a um tratamento: enxerto ósseo autólogo (EOA), controle negativo sem preenchimento (SP) e matriz óssea desmineralizada caprina (MODC).

\section{Preparo de MODC e Defeito Ósseo Crítico}

O preparo da MODC, a criação do defeito na ulna e o enxerto ósseo foram realizados segundo técnica modificada de Arpağ et al., ${ }^{10}$ Monazzah et al. ${ }^{11}$ e Bigham-Sadegh e Oryan. ${ }^{12}$

Coleta de Amostra de Sangue e Análise Hematológica As amostras de sangue foram coletadas antes da cirurgia para obtenção dos valores basais do hemograma completo e da contagem diferencial de leucócitos. As amostras de sangue foram coletadas por punção cardíaca sob anestesia com xilazina-quetamina. As amostras foram armazenadas em frasco com ácido etilenodiamino tetra-acético (EDTA; JRZ Plastilab, Beirute, Líbano) e processadas até 2 horas após a coleta, como adotado por Chineke et al. ${ }^{7}$ As amostras de sangue foram novamente coletadas no $28^{\circ}$ e no $56^{\circ}$ dia após a cirurgia, conforme Ajai et al., ${ }^{13}$ Bigham-Sadegh et al. ${ }^{14} \mathrm{e}$ Korkmaz et al. ${ }^{15}$ com modificações.

\section{Análise de Dados}

Os dados gerados foram analisados por uma abordagem de modelo misto de medidas repetidas com análise de variância (ANOVA) de dois fatores para detecção de diferenças na interação simultânea de dias e grupos, com nível de significância determinado como $p<0,05$, em InVivoStat 4.0 .2 (Chelmsford, Essex, UK).

\section{Resultados}

A cirurgia e o implante dos enxertos foram realizados com sucesso e os animais se recuperaram da anestesia sem intercorrências. Houve uma leucocitose global significativa $(p=0,0043)$ nos dias 28 e 56 em relação aos valores basais. No $56^{\circ}$ dia, uma diferença significativa também foi observada no número de neutrófilos $(p<0,0001)$. No $28^{\circ}$ dia, uma neutrofilia significativa foi observada no grupo MODC em comparação ao dia 0 ; o número de neutrófilos caiu no $56^{\circ}$ dia e não foi estatisticamente diferente de seu valor basal. Os grupos EOA e MODC apresentaram monocitose significativa no $28^{\circ}$ dia, com retorno aos valores basais no $56^{\circ}$ dia. Embora não tenha havido diferença estatística geral no número de linfócitos ( $p=0,4923)$, os grupos EOA e MODC apresentaram valores significativamente maiores no $28^{\circ}$ dia em comparação ao dia 0. Uma eosinofilia moderada foi observada nos grupos SP e MODC no $56^{\circ}$ dia. Uma diferença significativa geral também foi observada no número de hemácias $(p=0,003)$, concentração de hemoglobina $(p<0,0001)$ e hematócritos $(p<0,0001)$ ao longo dos dias nos diferentes grupos de tratamento. No entanto, não houve diferença global significativa no número de linfócitos $(p=0,4923)$, basófilos $(p=0,4183)$ e eosinófilos $(p=0,4806)$. Os resultados são apresentados na - Tabela 1, que mostra as diferenças significativas ao longo dos dias e entre os grupos.

\section{Discussão}

Como o sangue reflete o estado de saúde dos animais e as respostas à exposição a corpos estranhos e às doenças, ${ }^{1-7}$ usamos a hematologia para avaliação das respostas dos coelhos experimentais ao enxerto de MODC, que tem certa antigenicidade esperada. Vários relatos documentaram parâmetros hematológicos normais em coelhos de diferentes zonas geográficas e condições, ${ }^{4,7,8,16}$ mas a flutuação dentro das faixas fisiológicas normais dificulta seu uso diagnóstico, ${ }^{9}$ especialmente em coelhos, já que o sexo, o ritmo diurno, a raça, a temperatura ambiente, a idade e o estresse influenciam seus valores hematológicos. ${ }^{7,8,16}$ É, portanto, imperativo comparar as respostas hematológicas com os achados basais em qualquer condição experimental, como discutido em outros estudos. ${ }^{1,17,18}$

A leucocitose, que condiz com o estresse da cirurgia e a inflamação e a dor excruciante associadas à fratura e sua consolidação, 1,9,16,18,19 foi observada nos três grupos. A leucocitose intensa e significativa apresentada pelo grupo MODC no $28^{\circ}$ dia pode ser o resultado da reação imune à MODC implantada. O número de leucócitos caiu no $56^{\circ}$ dia e se aproximou ao valor basal, o que é indicativo de redução da reação ao implante. Este foi o mesmo padrão de reação observado para neutrófilos e linfócitos. Isso está de acordo com relatos anteriores ${ }^{16,20}$ de leucocitose com linfocitose acentuada em condições que desencadeiam respostas imunes.

Muitos fatores, como o horário da coleta de sangue e o estresse, influenciam o número de monócitos, eosinófilos e basófilos. ${ }^{16,20}$ Ainda assim, a monocitose condiz com a inflamação crônica em coelhos, ${ }^{16,20}$ como observado no grupo MODC no $28^{\circ}$ dia em comparação aos valores basais. A eosinofilia e a basofilia são marcadores de alergias e hipersensibilidades. A eosinofilia branda não foi observada neste estudo até o $56^{\circ}$ dia no grupo MODC. Isso pode ter sido causado pela redução da imunogenicidade do osso pelo processo de desmineralização. ${ }^{21,22}$

O menor número de hematócritos observado no $28^{\circ}$ dia em todos os grupos foi decorrente da perda de sangue à cirurgia. Isso está de acordo com relatos anteriores ${ }^{1,20}$ de anemia após hemorragia externa. No entanto, os animais de todos os grupos apresentaram aumento do hematócrito no $56^{\circ}$ dia, mas sem chegar aos valores basais correspondentes. Isso mostra que houve resposta regenerativa à perda de sangue. Da mesma forma, a concentração de hemoglobina também diminuiu no dia 28 e subiu até quase superar os valores basais no $56^{\circ}$ dia. Por outro lado, o número de hemácias aumentou nos dias 28 e 56 em todos os grupos à exceção do EOA no $28^{\circ}$ dia, no qual foi menor em comparação ao valor basal, sem significado estatístico. Os diferentes padrões observados para o número de hemácias podem ser decorrentes do tempo de coleta de amostra e da temperatura ambiente que influenciam os animais experimentais. ${ }^{16,20}$ 


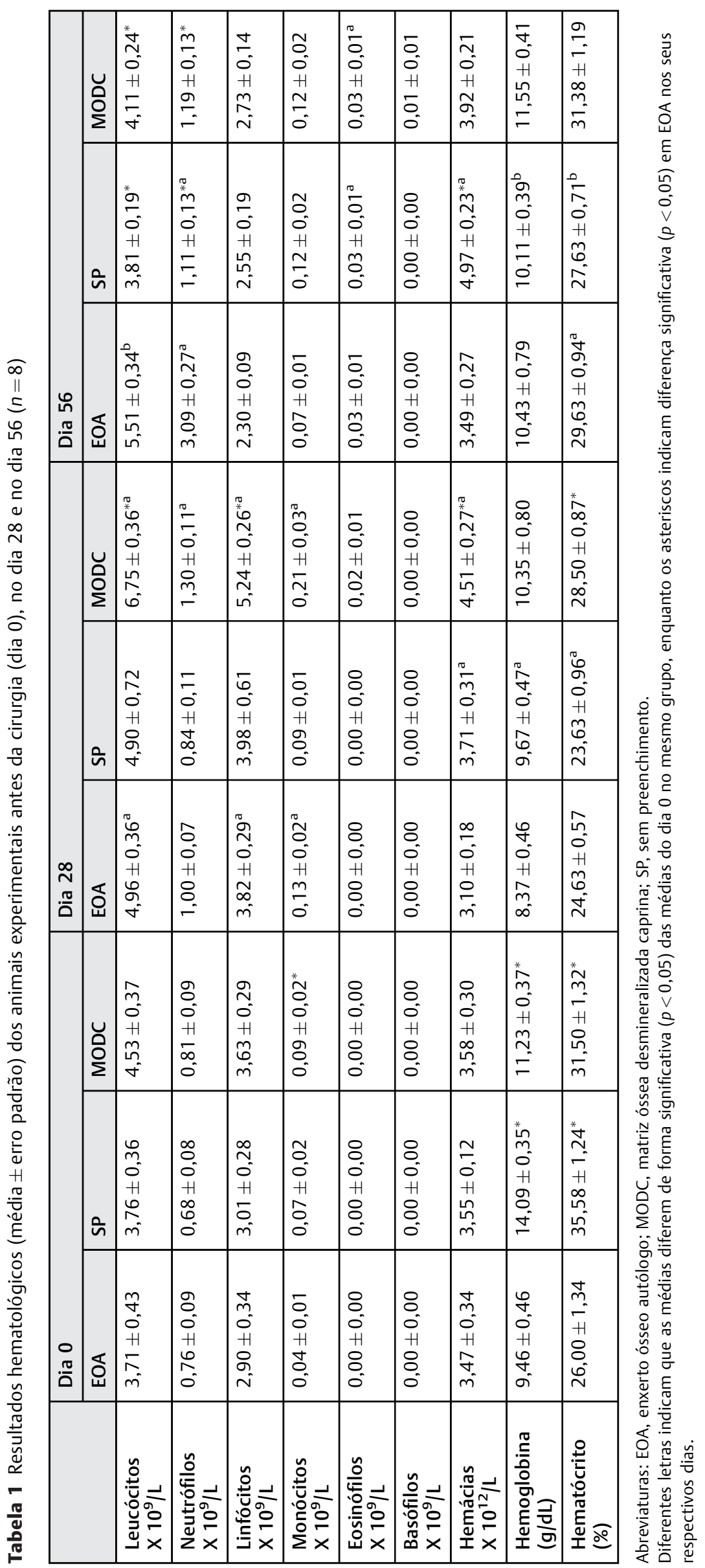


A incapacidade de monitorar o ritmo diurno e a temperatura ambiente em relação à variação dos valores hematológicos obtidos são as limitações deste estudo.

\section{Conclusão}

Apesar das várias flutuações que prejudicam a interpretação da análise hematológica em coelhos, este estudo concluiu que os animais responderam à MODC com leucocitose intensa com neutrofilia, linfocitose e monocitose no $28^{\circ}$ dia e retorno a valores próximos aos normais no $56^{\circ}$ dia após o procedimento. Estes dados podem, portanto, formar uma base hematológica para monitoramento do estado dos modelos animais de enxerto ósseo. No entanto, é fortemente recomendado que os valores basais sejam determinados em todos os estudos hematológicos em coelhos, considerando o ritmo diurno e a temperatura ambiente.

\section{Conflito de Interesses}

Os autores não têm conflito de interesses a declarar.

\section{Agradecimentos}

Os autores agradecem a assistência da equipe do Departamento e do Laboratório de Fisiologia Veterinária pelo ambiente propício à pesquisa.

\section{Referências}

1 Alimi OA, Abdulwahab WF, Amid SA, et al. Hematological prediction study of peritonitis following laparotomy in goats. J Vet Med Sci 2020;82(05):531-535

2 Tambuwal FM, Agaie BM, Bangana A. Haematological and Biochemical Values of Apparently Healthy Red Sokoto Goats. In: Proceeding of 27th Annual Conference. FUTA, Akure, Nigeria: Nigerian Society of Animal production (NSAP)2002:50-53

3 Akinrinmade JF, Akinrinde AS. Hematological and serum biochemical indices of West African dwarf goats with foreign body rumen impaction. Niger J Physiol Sci 2012;27(01):83-87

4 Etim NN, Williams ME, Akpabio U, Offiong EEA. Haematological Parameters and Factors Affecting Their Values. Agric Sci 2014;2 (01):37-47

5 Aderemi FA. Effects of replacement of wheat bran with cassava root sieviatesupplemented or unsupplemented with enzyme on the haematology and serum biochemistry of pullet chicks. Trop J Anim Sci 2004;7(01):147-153

6 Doyle D. William Hewson (1739-74): the father of haematology. Br J Haematol 2006;133(04):375-381

7 Chineke C, Ologun A, Ikeobi CO. Haematological Parameters in Rabbit Breeds and Crosses in Humid Tropics. Pak J Biol Sci 2006;9 (11):2102-2106
8 Moore DM, Zimmerman K, Smith SA. Hematological Assessment in Pet Rabbits: Blood Sample Collection and Blood Cell Identification. Clin Lab Med 2015;35(03):617-627

9 Kumar D, Bhargava MK, Singh R, et al. Haematological Changes during Fracture Healing in Goats. IOSR J Agric Vet Sci 2016;9(09): $1-3$

10 Arpağ OF, Damlar I, Altan A, Tatli U, Günay A. To what extent does hyaluronic acid affect healing of xenografts? A histomorphometric study in a rabbit model. J Appl Oral Sci 2018;26(00): e20170004

11 Monazzah S, Oryan A, Bigham-Sadegh A, Meimandi-Parizi A. Application of bovine bone versus bovine DBM graft on bone healing of radial defect in rat. Comp Clin Pathol 2017;26(06): 1293-1298

12 Bigham-Sadegh A, Oryan A. Selection of animal models for preclinical strategies in evaluating the fracture healing, bone graft substitutes and bone tissue regeneration and engineering. Connect Tissue Res 2015;56(03):175-194

13 Ajai S, Sabir A, Mahdi AA, Srivastava RN. Evaluation of Serum Alkaline Phosphatase as a Biomarker of Healing Process Progression of Simple Diaphyseal Fractures in Adult Patients. Int Res J Biol Sci Int Res J Biol Sci 2013;2(02):2278-3202

14 Bigham-Sadegh A, Mirshokraei P, Karimi I, Oryan A, Aparviz A, Shafiei-Sarvestani $Z$. Effects of adipose tissue stem cell concurrent with greater omentum on experimental long-bone healing in dog. Connect Tissue Res 2012;53(04):334-342

15 Korkmaz M, Oztürk H, Bulut O, Unsaldi T, Kaloğlu C. [The effect of definitive continuous distraction employed with the Ilizarov type external fixation system on fracture healing: an experimental rabbit model]. Acta Orthop Traumatol Turc 2005;39(03): 247-257

16 Washington IM, Van Hoosier G. Clinical Biochemistry and Hematology. The Laboratory Rabbit, Guinea Pig, Hamster, and Other Rodents.2012:57-116

17 Toth C, Klarik Z, Kiss F, Toth E, Hargitai Z, Nemeth N. Early postoperative changes in hematological, erythrocyte aggregation and blood coagulation parameters after unilateral implantation of polytetrafluoroethylene vascular graft in the femoral artery of beagle dogs. Acta Cir Bras 2014;29(05):320-327

18 Grover RK, Sobti VK. Clinical, haematological and radiological evaluation of fragmented autogenous cortical bone grafting of radius in dogs. Zentralbl Veterinarmed A 1998;45(05):303-308

19 Arens D, Wilke M, Calabro L, et al. A rabbit humerus model of plating and nailing osteosynthesis with and without Staphylococcus aureus osteomyelitis. Eur Cell Mater 2015;30:148-161, discussion 161-162

20 Melillo A. Rabbit Clinical Pathology. J Exot Pet Med 2007;16(03): 135-145

21 Guizzardi S, Di Silvestre M, Scandroglio R, Ruggeri A, Savini R. Implants of heterologous demineralized bone matrix for induction of posterior spinal fusion in rats. Spine 1992;17(06):701-707

22 Bigham AS, Shadkhast M, Bigham Sadegh A, Shafiei Z, Lakzian A Khalegi MR. Evaluation of osteoinduction properties of the demineralized bovine foetal growth plate powder as a new xenogenic biomaterial in rat. Res Vet Sci 2011;91(02):306-310 